\title{
Migración y Diseño \\ Proyecto de Investigación 13.3 \\ Equipo de Investigación
}

Marcia Veneziani-Ximena Gonzalez Eliçabe por Facultad de Diseño y Comunicación, Universidad de Palermo (ARG), Aotearoa Latin American Community ALACINC (NZ) y Museo de Arte Popular José Hernández-MAP (ARG) y Felicitas Luna-Mirta Bialogorski por Museo de

Arte Popular José Hernández-MAP (ARG)

Línea de Investigación 13.

Nuevos paradigmas en la enseñanza de la moda y el diseño.

Contextos económicos, sociales y culturales en la enseñanza del Diseño

\section{Resultados publicados en el [Cuaderno 111]}

Cuaderno del Centro de Estudios de Diseño y Comunicación $\mathrm{N}^{\circ} 111$. (2020/

2021) Migración y Diseño. Coordinación: Marcia Veneziani, Ximena González Eliçabe, Felicitas Luna y Mirta Bialogorski. Programa de Investigación de la Facultad de Diseño y Comunicación. Centro de Estudios en Diseño y Comunicación. Facultad de Diseño y Comunicación. Universidad de Palermo. Año XXIV, Buenos Aires, Argentina. ISSN: 1668-0227.

Los resultados de este Proyecto de Investigación fueron evaluados por Luz del Carmen Vilchis Esquivel y su Dictamen se transcribe a continuación:

\section{Síntesis de la Evaluación}

Actualidad de la temática (Vigencia, Aplicación) / Notable

Nivel Alcanzado (Profundidad, Consistencia, Jerarquía) / Notable

Diversidad del enfoques (Pluralidad, Participación) / Notable

Calidad (Problemática, Análisis, Tratamiento) / Buena

Contribución al avance del Diseño (Fortaleza) / Notable

\section{Fundamentos y Comentarios}

En el Cuaderno No111 se retoma como tema central "la migración", uno de los temas que resulta tan antiguo como la humanidad misma; desde los primeros grupos sociales los seres humanos hemos migrado por diversas razones, lo cierto es que en este trasiego no sólo han migrado individuos, sino también ideas, conceptos y elementos culturales. Son estos 
últimos los que interesan para el presente Cuaderno, pues tanto en el diseño como en la producción de estos está implícita la cosmovisión de quiénes participan en todo el proceso de elaboración; ejemplo de ello nos lo muestra el texto Migraciones en el diseño de mobiliario con perspectiva histórica. Antigüedad hasta el siglo dieciocho, de Girod, García de la Cárcova y Petrocchi, donde a través de un análisis histórico de la producción mobiliaria en diversas regiones, tanto de Europa como de América, se denota la influencia de las diversas regiones que conformaron el mundo de los siglos XVI, XVII y XVIII, donde no sólo la mirada europea tuvo cabida, sino que se mezcla con aspectos estéticos provenientes de las culturas originarias de América y el contacto posterior que se hizo con Oriente. Es en este tipo de aspectos donde la migración se vuelve un tema de reflexión, pues quien diseña y produce no siempre es quien ocupa o domina un determinado espacio, en este caso se observa la mano artesanal de quienes fueron ocupados por Europa; caso similar nos lo presenta el texto Una mirada desde la moda, de Andrea Lázaro, donde la producción de la "alta costura", se vuelve un escaparate para denunciar o problematizar los temas que surgen a partir de la migración; sin embargo, a diferencia de lo sucedido en el caso de la Europa de los siglos XVI al XVIII, el texto de Lázaro reflexiona el problema migratorio no desde quien migra para conquistar o establecer un dominio, sino más bien desde quién migra por necesidad, por temor o se ve obligado a abandonar su lugar de origen debido a la guerra, el hambre, la pobreza, etc.; en dicho artículo Lázaro nos ofrece una revisión a propuestas que surgen desde los mismos diseñadores, pues como bien apunta, "la moda es una vía de participación y de comunicación", siendo así un espacio para la reflexión sobre el hogar, el origen y la pérdida de éste pues "cuando el hogar se convierte en un lugar extraño, las prendas son el vestigio que llevamos puesto". Finalmente, se nos ofrece otra perspectiva a partir de textos como el de Felipe Forero, ALACINC y la construcción de la identidad latinoamericana en Nueva Zelanda: Un ejercicio de descolonización, donde quien diseña no es otro sino el migrante mismo, quién comparte por esta vía su cosmovisión enriqueciendo así un entorno que se vuelve multicultural, donde el diseño se torna un medio para establecer un diálogo entre distintas posturas, ideologías y costumbres, pues en este caso, si bien ALACINC nace de un grupo de migrantes chilenos, esta institución apoya a personas hispanoparlantes de diversos países, en un entorno completamente ajeno a la tradición latina, como lo es Nueva Zelanda. De esta manera se propone una reflexión, desde el diseño mismo, sobre el dolor, la angustia y la incertidumbre que provoca la migración. En suma, el Cuaderno $N^{\circ} 111$ nos invita a elaborar un análisis a conciencia sobre el tema migratorio, no sólo en sus aspectos estéticos, sino también humanos, pues en esta temática existen tanto dolor, como pérdida y cambios en las vidas de los individuos, los cuales no siempre son favorables para quienes son ocupados o para quienes deben abandonar su hogar. 